\title{
Populismo: ¿izquierdas y derechas?
}

\section{Populism, right-wing and left-wing position?}

PAULA BIGLIERI (Consejo Nacional de Investigaciones Científicas y Técnicas / Universidad de Buenos Aires)

Artículo recibido: 29 de diciembre de 2018

Solicitud de revisión: 25 de febrero de 2019

Artículo aceptado: 10 de abril de 2019

Biglieri, Paula (2020). Populismo: ¿izquierdas y derechas? Recerca. Revista de Pensament $i$ Análisi, $25(1)$, pp. 5-24.

\section{Resumen}

El artículo parte de la discusión actual sobre si la proliferación de los así denominados populismos de derecha invalida o no la tesis de Laclau de que el populismo es un tipo de articulación que puede dar un sentido emancipatorio a la iniciativa política. Dicho debate que se ha presentado fundamentalmente bajo la oposición binaria populismos de derechas frente a populismos de izquierda tiene a dos voces contrapuestas, las de Fassin y Mouffe, que el texto se propone revisar, desde una perspectiva laclausiana, a partir de dos preguntas que se desprenden de las posiciones políticas de los autores: ¿es posible, como desearía Fassin, eludir o eliminar el populismo? ¿Es posible distinguir entre un populismo de derechas y uno de izquierdas, como propone Mouffe?

Palabras clave: populismo, derechas, izquierdas.

\section{Abstract}

The article takes as a point of departure the current discussion about the proliferation of the so called right-wing populisms that put into question Laclau's thesis that populism is a sort of articulation that may bring about emancipatory directions to politics. This debate, that has recently taken the format of an opposition between right-wing populism vs. leftwing populisms, has two main competing voices - Fassin and Mouffe - that the text reviews from a Laclausian perspective. The two questions addressed, that rise from the political position of each author, are the following: is it possible to eliminate populism as Fassin would prefer? Is it possible to establish a differentiation between right-wing and left-wing populism as Mouffe affirms?

Key Words: populism, right-wing position, left-wing position. 


\section{INTRODUCCIÓN}

Desde la publicación en el 2005 de La razón populista, ningún estudio sobre populismo - que se precie de ser riguroso- ha eludido considerar, en un sentido u otro, el trabajo que en ese texto desarrolló Ernesto Laclau. No resulta sorprendente, ya que se trató de una intervención que estableció un punto de inflexión en el tratamiento del tema y, en consecuencia, modeló el marco general dentro del cual se desarrolla desde entonces el debate en torno al populismo. La importancia de la obra de Laclau puede resumirse de la siguiente manera: logró darle el estatuto de categoría política a un término hasta entonces mayormente ignorado o, si tenido en cuenta, tratado con desdén por gran parte del mundo académico y también político.

El logro de Laclau se enmarcó dentro de un propósito más amplio que, según el autor, conformó «un proyecto único: retomar la iniciativa política, lo que desde mi punto de vista teórico, significa hacer la política nuevamente pensable» (Laclau, 2008: 12).

En efecto, todo el desarrollo teórico de Laclau, desde aquel puntapié inicial del posmarxismo que diera junto con Chantal Mouffe en 1985 a partir de la publicación de Hegemonía y estrategia socialista. Hacia una radicalización de la democracia, debe ser leído en este sentido. La propuesta de análisis de discurso de la teoría de la hegemonía y el antagonismo que comenzó a elaborar con la autora belga, su reformulación de los conceptos de reactivación y sedimentación, sus posteriores nociones de dislocación, heterogeneidad, pueblo, lider y populismo se comprenden en un mismo doble movimiento: por un lado, en clave teórica, como un intento de devolverle a la política su lograr primordial y, por otro lado, en clave política, como una insistencia en la iniciativa política como clave para la emancipación. Hay que subrayar que el populismo adquirió en este doble movimiento un lugar fundamental.

Ahora bien, dados los crecientes casos de formaciones políticas que han sido denominados como populismos de derechas (que en diversas latitudes del globo han dado lugar a gobiernos que han enlazando políticas neoliberales con posiciones xenófobas, racistas, sexistas, homofóbicas, antifeministas, etc. $-\mathrm{y}$ aquí por mencionar solo algunos ejemplos podemos listar a Donald Trump en los Estados Unidos de América, a Viktor Orbán en Hungría, a Recep Tayyip Erdoğan en Turquía y a Jair Bolsonaro en Brasil_), la discusión sobre si el populismo es efectivamente un tipo de articulación que puede dar un sentido emancipatorio a la iniciativa política ha adquirido renovada centralidad y ha puesto en cuestión la tesis política de Laclau. 
Nos proponemos en este artículo problematizar dos aspectos que abonan la discusión sobre del carácter emancipador (o no) del populismo. Lo haremos tomando dos posiciones políticas contrapuestas, las de Mouffe (2018) y Éric Fassin (2018), que se han manifestado recientemente y representan la forma en que este debate se ha presentado últimamente, a saber: bajo la oposición binaria populismos de derechas frente a populismos de izquierda. Mouffe defiende la conformación de populismos de izquierda como estrategia política para la coyuntura actual de la Europa occidental, mientras que Fassin impugna el populismo en cuanto tal. Así, desde una perspectiva laclausiana, buscaremos puntualmente repasar dos preguntas que se desprenden de las posiciones políticas de estos autores: ¿es posible, como desearía Fassin, eludir o eliminar el populismo? ¿Es posible distinguir entre un populismo de derechas de uno de izquierdas, como propone Mouffe? Ahora bien, antes de adentrarnos en estos dos puntos, trazaremos un mapa mínimo de los estudios sobre el populismo hasta desembocar en los autores involucrados en la discusión propuesta.

\section{PRIMER NIVEL: POPULISMO, UN MAPA MÍNIMO}

Si rastreamos los trabajos más destacados sobre el populismo, podemos organizarlos en torno a tres grandes ejes: la modernización, la lucha de clases y la política.

Las lecturas tradicionales de la sociología de la modernización caracterizaron el populismo desde una perspectiva funcionalista y lo asociaron a una fase particular del desarrollo social. El trabajo clásico dentro del primer eje es el de Gino Germani (1968). Este autor consideraba que el populismo cumplía la función - propia de los países en desarrollo- de facilitar el tránsito de una sociedad tradicional a una moderna. A partir de un análisis del caso argentino de las décadas de 1930 y 1940, sostuvo que el proceso de industrialización y urbanización creó masas disponibles para la acción política, cuya intervención temprana en la política habría perturbado el tránsito adecuado (pautado por el modelo europeo) hacia la modernización y, con ello, también conmocionado las formas institucionalmente apropiadas de la democracia liberal. Desde entonces, el sello que ha determinado esta perspectiva es el de considerar el populismo como una anomalía ajena al buen funcionamiento liberaldemocrático, que debe ser evitado o, en su defecto, una vez acontecido, corregido. 
Dentro del segundo eje, el argumento clásico sostuvo que el populismo era una expresión de una alianza interclasista que no se avenía al formato esperable de la lucha de clases. El populismo era así considerado también como una suerte de desviación de un patrón esperado; en este caso, la clase trabajadora no seguía el camino correcto que le era indicado en tanto clase social y abandonaba su tarea fundamental e históricamente asignada, a saber: la lucha anticapitalista. Este argumento atravesó a los análisis tradicionales que hicieron al populismo indistinguible del bonapartismo y también a aquellos trabajos que — al considerar los casos de Italia en la década de 1920 y de Alemania en 1930volvieron al populismo inseparable del fascismo.

Posteriormente, Miguel Murmis y Juan Carlos Portantiero (1971) presentaron una lectura más sofisticada y sostuvieron que el populismo, lejos de mostrar irracionalidad de parte de la clase obrera, expresa su pragmatismo. En todo caso, a partir del análisis del surgimiento del peronismo en Argentina, sostuvieron que se trató de una alianza entre la clase obrera y los pequeños empresarios, que contó además con el soporte del Estado. Es decir, aunque el peronismo haya representado el proyecto hegemónico de los pequeños empresarios y la burocracia estatal, para la clase obrera de todas formas implicó la realización de sus demandas en torno a la distribución del ingreso y una extensión de sus derechos en múltiples dimensiones.

El trabajo de Slavoj Žižek (2009) presentó una renovada versión de la crítica del marxismo al populismo, pasada por el tamiz del psicoanálisis. Sostuvo que el populismo nunca puede poseer un carácter emancipador porque básicamente, siempre encierra una tendencia protofascista. Su argumento consiste en una lectura crítica de Laclau, de quién acepta que el populismo pueda ser considerado una lógica abstracta — formal — de la política, que puede expresar diversos contenidos, pero rechaza que esa lógica abstracta necesite del suplemento pseudoconcreto de una figura que encarne al enemigo responsable de los males del pueblo. El problema, según Žižek, sería que los populismos proyectan el antagonismo constitutivo de lo social sobre un enemigo concreto - cuya destrucción traería la justicia al pueblo- en lugar de enfocarse en el sistema (capitalista) en cuanto tal. Así, el pueblo del populismo siempre sería un pueblo unificado en la medida en que necesita de un enemigo con el cual antagonizar. En todo caso, para Žižek, al igual que para las diversas posiciones marxistas, el populismo sería una suerte de distracción que aleja a la clase obrera de su propio y definitivo objetivo histórico de clase: destruir al capitalismo y avanzar hacia la sociedad emancipada. 
En el tercer eje, conformado por aquellos que han trabajado el populismo desde su dimensión política, pueden considerarse diversas aristas. Una primera es la de aquellos autores que trabajaron la relación del populismo con la democracia. Los trabajos clásicos son los de Peter Worsley (1969) y Margaret Canovan (1999). La novedad de estos textos radicó en que ninguno de los autores tomó al populismo como una amenaza para la democracia o como algún tipo de desviación. Para Worsley, el populismo demostró que la democracia representativa redujo la participación a una mera cuestión formal y, en consecuencia, rescató el valor de la participación por sobre sus procedimientos institucionales. En este sentido, consideró que la relación propiamente populista entre el líder y el pueblo refiere a una idea general de participación que no debe ser juzgada a priori como un defecto autoritario sin tener en cuenta el contexto de emergencia. Canovan, por su parte, reforzó este argumento cuando afirmó que el populismo es una dimensión constitutiva de la democracia que emerge en la brecha inerradicable que todo régimen liberal-democrático tiene entre sus dos caras, la redentora y la pragmática. Se trata, además, de una mera forma que implica una apelación al pueblo en contra de las estructuras dominantes de poder, cuyo contenido dependerá del contexto en el cual se movilice. Una segunda arista es la de aquellos autores que han problematizado la relación del populismo con el republicanismo. Es decir, la de quienes consideran que el populismo posee una relación contrapuesta o de exterioridad con el republicanismo y quienes, por el contrario, ligan el populismo con la tradición republicana. Entre estos últimos encontramos el trabajo de Eduardo Rinesi (2015), quien considera que el populismo «no es solo conflicto y crisis de todos los poderes instituidos, sino también cierre, hegemonía, orden, institucionalidad» (Rinesi, 2015: 91). Recrimina entonces a Laclau haber cargado demasiado las tintas en el rasgo antagonista del populismo en detrimento de la institucionalidad y, para sustentar su argumento, baraja como ejemplo la última oleada de gobiernos latinoamericanos — particularmente en el caso del kirchnerismo- que, con su política de ampliación de derechos, habría propiciado una vigorización de las instituciones republicanas del Estado. Es más, considera que incluso si se eligiera acentuar (como Laclau) el rasgo antagonista de los populismos, esto no anula su tesis respecto de la relación entre populismo y republicanismo, ya que existe una larga tradición que enfatiza la dimensión conflictual y rupturista de la república. Baste para ello recordar al propio Maquiavelo, quien consideraba que los disturbios y los tumultos eran: «[...] como la savia vital de esas instituciones, como lo que las habían hecho robustas 
y fuertes, y como lo que les permitía renovarse y perfeccionarse todo el tiempo» (Rinesi, 2015: 91).

La cosa pública siempre es, en un punto, conflictual. En todo caso, para Rinesi, populismo y republicanismo no mantienen una relación de mutua exclusión, sino un vínculo complejo en la medida en que abrevan en elementos comunes (el institucionalismo y el rupturismo). De allí que haya que descartar que el populismo es meramente lo otro de las instituciones a las cuales siempre va a amenazar.

Por esta misma línea se deslizan los argumentos de Valeria Coronel y Luciana Cadahia (2018) quienes destacan la importancia de indagar qué tipo de institucionalidad genera el populismo sin perder de vista, por un lado, que este apunta a construir un Estado que dé cuenta de la irrupción de las masas populares en la política y, por otro lado, su dimensión intrínsecamente democrática en la medida en que: «[...] el populismo es una de las pocas experiencias políticas que mantiene viva la figura de un pueblo empoderado» (Coronel y Cadahia, 2018: 77).

A partir del análisis de estos dos aspectos, las autoras defienden la idea de que el populismo encarna un republicanismo plebeyo que pone en acto la dimensión conflictual de las instituciones como mecanismo de ampliación de derechos. Coronel y Cadahia encuentran por esta vía el argumento que les permite sostener la misma tesis política que Laclau: el populismo puede adquirir una dimensión emancipatoria. En efecto, identifican que el populismo puede tener tanto una dimensión reactiva como emancipadora. Si la primera se caracteriza por un ejercicio inmunitario que intenta eliminar cualquier elemento amenazador al cual le son achacados los males del pueblo y apunta a recuperar una plenitud perdida, la segunda, por el contrario, se constituye a partir del lazo plebeyo, la igualdad entre los de abajo, que se despoja de cualquier intento inmunitario a la vez que mantiene el antagonismo con los de arriba. Así pues, en la matriz plebeya, de corte republicano-populista que encarna la dimensión emancipadora, las autoras consideran que «las instituciones son concebidas en su dimensión igualitaria como el espacio propicio para la expansión de derechos y la desarticulación de la frontera material entre los de arriba y los de abajo» (Coronel y Cadahia, 2018: 78).

Y aquí confluye la tercera arista, la de la orientación política de los populismos, vale decir, aquella que aborda el problema de si los populismos pueden tener (o no) una dimensión emancipatoria, es decir, si pueden ubicarse a la izquierda del espectro político. Señalamos que el debate ha encontrado recientemente dos voces que se han destacado y que defienden posiciones contra- 
puestas: una es la de Mouffe (2018), que defiende al populismo de izquierda como una estrategia política válida para las democracias de Europa occidental. Estos abrirían la posibilidad para una extensión democrática (en tanto que defienden la igualdad y la soberanía popular, elementos constitutivos de toda democracia) en un contexto de crisis de la hegemonía neoliberal y la emergencia de populismos de derecha — autoritarios y antidemocráticos-. La otra voz es la de Fassin (2018) quien no solo descarta la posibilidad de un populismo emancipador o de izquierda, sino que rechaza de cuajo cualquier tipo de expresión populista. Su posición política es la de combatirlos y, en relación con los populismos de izquierda, nos advierte que impulsar su formación no tiene ningún sentido, ya que el populismo en cuanto tal carece de cualquier rasgo progresista, de izquierda o democratizador en la medida en que ha demostrado que, además de autoritario, puede ser compatible con el neoliberalismo. En todo caso, considera que fomentar la creación de populismos de izquierda como estrategia política para enfrentar el neoliberalismo y los populismos de derecha es un error, en la medida en que no se trata meramente de convertir a los votantes populistas de derecha en votantes populistas de izquierda. Sino que una estrategia de izquierda debería ir a buscar a los no votantes y no intentar seducir de los votantes populistas de derecha con apelaciones a elementos tales como la nación o la patria, que lo único que pueden alentar es la reafirmación de posiciones reaccionarias.

Ahora bien, a pesar de sus divergencias, ambos autores poseen puntos en común. En primer lugar, tienen los mismos enemigos/adversarios: los populismos de derecha y el neoliberalismo. En segundo lugar, comparten un diagnóstico: afirman que Europa occidental vive un momento populista, aunque difieren en su definición. Para Mouffe, el momento populista tiene lugar: «[...] cuando bajo la presión de transformaciones políticas o económicas, la hegemonía dominante es desestabilizada por la proliferación de demandas insatisfechas» (Mouffe, 2018: 11).

Este momento, además, sería consecuencia de una situación posdemocrática a la cual se llegó en gran medida gracias a que las socialdemocracias abrazaron la agenda neoliberal y, en consecuencia, dejaron sin alternativas de intervención política a la ciudadanía, a lo que debe añadírsele que son responsables de la creciente oligarquización de las sociedades europeas después de la crisis financiera del 2008. Fassin, por su parte, concuerda con Mouffe en echar responsabilidades por el contexto actual europeo a las socialdemocracias, aunque define al momento populista por el hecho de que ahora también la izquierda reclama para sí la etiqueta populista. En tercer lugar, ambos autores 
plantean sus análisis en función de una estrategia política para Europa occidental, es decir, sus textos corresponden a un estudio de caso. Y, en cuarto lugar, ninguno de los dos busca desarrollar argumentos teóricos. Fassin porque reproduce el desdén hacia el populismo cuando lo desecha como categoría teórica y, en consecuencia, procura evitar, según sus propias palabras: «[...] dar una definición general de populismo porque no intento elaborar esta noción como un concepto teórico. Estoy más interesado en los usos políticos del término» (Fassin, 2018), afirmación que posiblemente explique la poca claridad con que hace uso del término y el porqué de su apuesta política. Mientras que Mouffe, al plantear su defensa del populismo de izquierda, de alguna manera soslaya el punto que la propia teoría que ella defiende subraya: que el populismo no es meramente una estrategia política.

\section{LA IMPOSIBLE ERRADICACIÓN DEL POPULISMO}

Vayamos entonces a la primera pregunta. Mencionamos líneas atrás que el proyecto teórico y político de Laclau, según sus propias palabras, tenía como objetivo «hacer la política nuevamente pensable» (Laclau, 20o8: 12). Al profundizar en la línea argumentativa de esta afirmación, estamos en condiciones de sostener que Laclau fue un pensador de la política o un pensador político antes que un filósofo político. Más aún, incluso podemos aventurar la conjetura de que Laclau nunca hubiese aceptado que su trabajo fuese clasificado como un ejercicio de filosofía política, simplemente por el hecho de que Laclau nunca admitió que la política fuera un mero subsistema de la filosofía. Es decir, nunca estuvo de acuerdo con aquellas posiciones que consideran que la política posee un campo disciplinar delimitado con bordes claros, una definición diáfana y distintiva, o posee a priori un objeto de estudio preciso para ser examinado, por ejemplo, las formas institucionalizadas de intercambio. Para Laclau la política va mucho más allá de las formas institucionalizadas de intercambio, también hay lo político, que tiene un lugar absolutamente decisivo en su teorización. En efecto, lo político es el momento en el cual la objetividad misma toma forma, es decir, lo político fue entendido por Laclau como el momento de la constitución de la realidad en cuanto tal.

Laclau se sumó así a aquellos autores que consideran la política en su doble inscripción: lo político y la política. Podríamos decir que la política es la forma institucionalizada, es decir, prácticas circunscriptas a ciertos ámbitos de aparición y sectores de actividades específicos. Y lo político tiene que ver con 
la puesta en forma de lo social, es aquello que instituye lo social, por lo tanto, difícilmente pueda ser fijado a un subsistema o esfera en particular. Lo político excede el ámbito institucional de la política y permea todo el orden en cuanto tal. Para ser más precisas, es en Nuevas reflexiones sobre la revolución de nuestro tiempo, un texto de 1990, en donde planteó la primacía de lo político a partir de una reformulación de los conceptos de sedimentación y reactivación de Husserl. La doble inscripción de lo político supone la relación entre sedimentación (lo social como momento de lo instituido) y reactivación (lo político como momento de la institución).

Pues bien, para Laclau toda comunidad (orden, objetividad, identidad e incluso la universalidad) es siempre políticamente instituida. Y políticamente instituida significa hegemónicamente articulada. Entonces, podríamos decir que para Laclau lo político es ontológico. Sin embargo, cabe aclarar que sería un error pensar a lo político meramente como una formación hegemónicamente articulada, sino que se trata también de considerar su conformación siempre en relación con el antagonismo. Aquello que Laclau y Mouffe (1985: 164) definieron como «la experiencia del límite de toda objetividad». En términos del psicoanálisis lacaniano, podemos decir que no hay que pensar en lo político solamente en términos de los registros simbólico-imaginarios, sino en relación con lo real, o más bien atravesado o permeado por lo real. Lo político tiene que ver con un hacer con el antagonismo. Entonces, si pensamos que la hegemonía (lo político) para Laclau siempre se estructura alrededor de un núcleo traumático no dialectizable (el antagonismo, que pone a trabajar a las dimensiones sociosimbólicas), nos estamos desplazando hacia algo así como un fundamento de lo real. Esto último resulta una afirmación cuanto menos polémica - por no decir contradictoria - en la medida en que Lacan rechazó la ontología, pero en todo caso es en ese juego entre antagonismo y hegemonía en donde habría que pensar la primacía de lo político en Laclau. ${ }^{1}$

Ahora bien, si continuamos con la ilación de sentido respecto de lo político como hegemónicamente articulado, también podemos afirmar, siguiendo a Laclau, que la hegemonía es su forma misma y que está atravesada por dos lógicas que la constituyen, la lógica de la diferencia y la lógica de la equivalencia, que encuentran un límite en el antagonismo. Y si consideramos estos supuestos teóricos a la luz del vínculo entre política y populismo, podemos decir

\footnotetext{
La postura de Lacan de rechazo a la ontología puede rastrearse en diversos pasajes de su obra. Véase, por ejemplo, el capítulo VIII del seminario XX, Aün, o el seminario XI, Los cuatro conceptos fundamentales del psicoanálisis.
} 
que si Laclau entendió la política como la práctica de la hegemonía, también afirmó que «el populismo es sencillamente una manera de construir lo político» (Laclau, 2005: $\mathrm{x} 1$ ), es decir, es una forma de la práctica hegemónica misma.

Esta aparente confusión entre populismo y política abrió el espacio para lecturas contrapuestas. Empujó a algunos autores, como por ejemplo Benjamín Arditi (2003, 2005), a afirmar que la teoría de Laclau resultaba redundante y carente de especificidad conceptual, ya que manejaba tres términos que se sobreponían semánticamente: hegemonía, política y populismo; lo que, en definitiva, solo habría traído más confusión sobre el concepto de populismo. Por otro lado, llevó a un autor como Oliver Marchart (2018) a defender la tesis de que el populismo es el corazón de la política. Marchart celebró cómo la radicalidad de la noción laclausiana de antagonismo - en tanto que ejercicio de la negatividad- permitió establecer que el populismo no es simplemente una forma política entre otras sino: «[...] su más clara expresión ya que encapsula la racionalidad política tout court en la medida en que responde a la lógica del antagonismo» (Marchart, 2018: 23).

Así, si el populismo es la forma política que cabalmente responde a «la lógica del antagonismo», entonces resulta ser su forma fundamental, ya que para Marchart el antagonismo es el nombre de lo político mismo porque este es justamente su rasgo definitorio.

En otros textos ya hemos sostenido que no coincidimos con la lectura de la superposición semántica, sino que proponemos pensar la cuestión en términos de contaminación (Biglieri y Guille, 2017). Pero también debemos mencionar que nuestra posición, si bien es cercana a la de Marchart en la medida en que consideramos que efectivamente todo antagonismo es político, además entendemos que este debe ser construido políticamente para que adquiera entidad. Debe haber una construcción simbólico-imaginaria que dé cuenta de él. En otras palabras, no hay «la lógica del antagonismo» si no es en relación con las lógicas de la equivalencia y de la diferencia, porque es solamente a través de estas que podemos dar cuenta de aquel. Es en este sentido en el que líneas atrás mencionamos que lo político es un hacer con el antagonismo.

Pues bien, nuestro argumento respecto de la contaminación entre populismo y política se basa en que cada articulación populista en cuanto tal está atravesada por la lógica de la equivalencia y la lógica de la diferencia y, además, genera efectos de frontera a partir de la puesta en acto de algún antagonismo. Estas dos lógicas -que no pueden ser encastradas de manera coherentemente unificada-y los efectos de frontera son constitutivos de la política y del populismo, de allí su mutua contaminación. Así, una vez que hemos introducido la 
noción de contaminación, sabemos que la posibilidad de delimitar áreas conceptuales de manera pura y prístina queda cancelada. Sin embargo, es aún posible establecer ciertos rasgos definitorios del populismo, a saber: a) la primacía de la lógica de la equivalencia sobre la de la diferencia que posibilita la construcción de una subjetividad política más amplia —el pueblo-; b) la dicotomización antagonista del espacio social en dos lugares de enunciación sobredeterminados -el pueblo frente a los enemigos del pueblo- y c) la emergencia de un líder.

No podemos, entonces, pensar la política como inmune a la emergencia del populismo, ni mucho menos bregar por su definitiva eliminación. El populismo la contamina, está inscripto en ella misma y, por lo tanto, también el pueblo y sus liderazgos. En todo caso, podemos tener articulaciones hegemónicas no populistas que se formen a partir de una diversidad de antagonismos con la ausencia de un liderazgo determinante que nomine a un pueblo o bien podemos encontrar formaciones políticas en donde haya un privilegio de la lógica de la diferencia y de una absorción institucionalizada de demandas; pero no debemos perder de vista que siempre está allí alojada la posibilidad de que la diversidad de antagonismos en cierto punto se simplifique en torno a dos cadenas de equivalencias (el pueblo frente a sus enemigos) que dividan dicotómicamente el espacio social, al igual que el surgimiento de liderazgos que le impriman un nombre al pueblo dando cuenta de su singularidad. ¿Acaso la historia no ha sido testigo en infinidad de oportunidades del surgimiento de este tipo de articulaciones?" Así, una vez que podemos capturar la idea de que el populismo abreva en aquellos elementos que son condición misma de la política, entonces entendemos por qué Laclau afirmó que el gesto populista es «la vía real para comprender algo relativo a la constitución ontológica de lo político como tal» (Laclau, 2005: 91).

Pareciera que los sueños de eliminar el populismo - que provienen tanto de posiciones de derechas como de izquierdas ya sea en el ámbito académico como en la arena política misma-, encuentra sus raíces en un viejo anhelo platónico nutrido de un rechazo de la política misma y en: «[...] la afirmación

2 Por mencionar algunos ejemplos: el boulangismo en Francia, el movimiento narodniki en Rusia y el Partido del Pueblo en el sur de los Estados Unidos de América a fines del siglo XIX; el primer Ibañismo en Chile o el Yrigoyenismo en Argentina de comienzos del siglo XX; el Estado Novo de Brasil, el Cardenismo mexicano, el Peronismo en Argentina, el Movimiento Nacional Reformista de Bolivia, el Nasserismo en Egipto, promediando el siglo XX; la última oleada de populismos latinoamericanos con Lula y Dilma Rousseff en Brasil, Néstor y Cristina Kirchner en Argentina, Rafael Correa en Ecuador, Hugo Chávez Frías en Venezuela y Evo Morales en Bolivia; SYRIZA en Grecia, Podemos en España o la Francia Insumisa de JeanLuc Mélenchon. 
de que la gestión de los asuntos comunitarios corresponde a un poder administrativo cuya fuente de legitimidad es un conocimiento apropiado de lo que es la 'buena' comunidad» (Laclau, 2005: 10).

Así pues, después de la intervención teórica de Laclau, es difícil sostener sin más argumentos que consideran que el populismo es una forma política menor, fallida, desviada y marginal que debe ser evitada o eliminada por perturbar o interrumpir el buen funcionamiento racional de la comunidad o considerarlo un problema que acontece solo en ciertas regiones del planeta. Nos cabe considerar entonces que seguir defendiendo este tipo de lecturas demuestra de parte de quien la sustenta o bien cierta pereza intelectual o una suerte de desprecio o incluso odio (político) hacia el pueblo como sujeto político que viene a alterar aquello que considera el buen orden y las buenas maneras.

En todo caso, podemos decir que una articulación política determinada puede desarticularse, un determinado pueblo con su líder pueden ser derrotados políticamente, pero el populismo en tanto forma de la política, es inerradicable. Es decir, en un sentido óntico, en tanto que una articulación ligada a una determinada forma de expresión política en un específico contexto, una formación populista bien puede terminar. En cambio, en un sentido fundamental, ligado a la forma misma de la política, el populismo es sencillamente inerradicable. Malas noticias para Fassin.

\section{SIN MÁS: POPULISMO}

Avancemos sobre la segunda pregunta: ¿es posible distinguir entre un populismo de derechas y uno de izquierdas como propone Mouffe? La autora, al desarrollar su argumento en defensa de los populismos de izquierda — si bien elude en su texto una discusión teórica sobre el populismo-, se toma el trabajo de aclarar algunos supuestos teóricos que subyacen en su posición política. Por un lado, remarca el carácter partisano de la política. Es decir, la defensa del carácter constitutivamente político y, por lo tanto, parcial, precario y negociable de toda objetividad e identidad en oposición a aquellos enfoques que sostienen que la política es el gerenciamiento neutral de los asuntos públicos, la hegemonía pospolítica impuesta por Margaret Thatcher de que «no hay otra opción posible» seguida por la defección de la socialdemocracia (Mouffe, 2018: 4). Y, por otro lado, el carácter antiesencialista de la postura teórica que construyó con Laclau y en la cual se apoya. 
Aclarados estos aspectos, Mouffe nos ofrece, como ya hemos señalado, su diagnóstico de los tiempos que corren en Europa occidental -el momento populista- en el que apuesta por la construcción de un populismo de izquierda. Apoyándose entonces en el carácter antiesencialista en el cual se basa, propone disputarle ciertos significantes a los populismos de derecha. Es decir, interpelar a los votantes de los populismos de derecha, ya que, en la medida en que no hay un esencialismo identitario irreductible, esos mismos votantes pueden verse convocados por un llamado desde la izquierda. La hipótesis que subyace a este planteo de Mouffe es que la emergencia de la pospolítica volcó a muchos sectores sociales afectados por el neoliberalismo hacia los populismos de derecha, en la media en que se mostraron como las únicas alternativas disponibles, justamente, frente a la omnipresencia de aquel mandato. En este sentido, muchas de las demandas articuladas por los populismos de derecha serían demandas democráticas, que provienen de los perdedores de la globalización neoliberal, cuyas reivindicaciones justamente no pueden ser absorbidas por ese mismo neoliberalismo. En todo caso, para Mouffe, una vez que las socialdemocracias aceptaron el terreno hegemónico impuesto por el neoliberalismo y jugaron un rol decisivo en la implementación de sus políticas —al abandonar la oposición izquierda/derecha y provocar una convergencia al centro- lo que generaron es un distanciamiento de los ciudadanos de la política ya que estos se quedaron sin alternativas políticas posibles frente a lo que se les apareció como un destino ineludible, un statu quo inapelable. Si los populismos de derecha rompieron con esta falta de alternativas y ganaron el voto de vastos sectores sociales, ahora es el turno de los populismos de izquierda para dar un giro democrático, en pos de la justicia social e igualitario a esa alternativa al neoliberalismo.

Así pues, Fassin, con su crítica, pierde por completo de vista aquello que Mouffe se toma muy enserio: el antiesencialismo. Entonces, así como desde una postura antiesencialista consistente partimos del supuesto de que ninguna demanda es en sí emancipatoria - sino que depende de una articulación más amplia - tampoco esto cabe para significantes tales como estado o patria, más allá de que en el contexto europeo tradicionalmente han estado asociados a los discursos de derechas. La orientación política de esos elementos (o, más bien, de cualquier elemento) depende de una articulación política más amplia. Contrario a lo que sustenta Fassin (que parece caer en la trampa esencialista y sostiene que la izquierda con esos significantes no tiene nada que hacer ya que le corresponden intrínsecamente a la derecha), la apuesta en la disputa política (hegemónica) es más bien la de desarmar a los populismos de derechas, arreba- 
tándole las demandas democráticas que articulan y también aquellos elementos (Estado, patria) de los que se han apropiado y que fungen como sus puntos nodales y dotarlos de nuevos sentidos.

Dicho esto, es interesante puntualizar que Laclau afirmó que la orientación política que pueda adquirir un determinado populismo dependerá de la correlación de fuerzas del contexto dado. Sin embargo, nunca sostuvo que esa orientación debía basarse en la distinción izquierda/derecha, ni mucho menos estableció cuales serían los rasgos fundamentales para entablar una distinción binaria en esos términos. Como ya lo afirmamos líneas atrás, el populismo es una forma de la política tan vieja como la política misma, que, nutriéndose de sus dimensiones constitutivas, viene a conmover el statu quo a través de la formación de una larga cadena de equivalencia que opone el pueblo a sus enemigos, o los de abajo contra la oligarquía o las élites. Ahora bien, Mouffe sí establece ciertos contenidos para su distinción. Después de establecer el diagnóstico de que frente al cuestionamiento de la pospolítica se abre el momento populista que tendrá como eje central del conflicto político entre la oposición populismo de derecha frente a populismo de izquierda, nos dice que los populismos de izquierda deben apuntalar una posición democratizadora que defienda la igualdad y la justicia social, mientras que los populismos de derecha defienden posiciones autoritarias, racistas y xenófobas y, en consecuencia, contrarias a cualquier anhelo igualitario. Se trata entonces de construir un pueblo que resulte de la movilización de afectos comunes y reavivar la vieja distinción entre izquierda y derecha; pero esta última definida ya no como tradicionalmente lo hizo la izquierda a partir de determinadas categorías sociales, sino en términos de la articulación de una heterogeneidad de demandas que no necesariamente tienen un anclaje de clases.

El cuestionamiento que aquí se podría plantear a la argumentación de Mouffe es si no está pensado el populismo de izquierda como el reverso negativo del populismo de derecha. Es decir, el populismo de derecha e izquierda como anverso y reverso de una misma hoja de papel. Así, en el momento populista que se habría abierto como respuesta a la antipolítica, se impone como estrategia política para la izquierda la construcción de una voluntad colectiva (el pueblo) a partir de la movilización de afectos en común. En este sentido, la posición de Mouffe sería - en definitiva - la de frenar a los populismos de derechas, que bien habrían sabido valerse del momento populista, con la construcción de uno de izquierda. A Fassin, en cierta medida, en este punto le asiste la razón, cuando destaca que en la actual coyuntura de ascensos de 
(populismos) de ultraderecha no se trata meramente de trasladar los votantes desde un populismo a otro.

Creemos que el problema yace en la distinción que Mouffe propone para diferenciar entre populismos de izquierda y derecha. La diferencia no radica en que los populismos de derecha «no responden a la demanda por igualdad y construyen un pueblo que excluye numerosas categorías» (Mouffe, 2018: 24) y los populismos de izquierda si responden a la igualdad y son inclusivos, porque, en todo caso, el populismo siempre da cuenta de la igualdad. Todo populismo, llámese de izquierda o derecha, desde el punto de vista de su estructuración constitutiva - si seguimos el argumento de Laclau- está atravesado o conformado por una lógica igualitaria en la medida en que responde a un privilegio de la lógica de la equivalencia. Sabemos por Laclau y también por la propia Mouffe que las cadenas de equivalencia se articulan no porque las particularidades que las conforman tengan un objetivo en común, pues los elementos implicados se definen negativamente, como diferencias. Sus demandas particulares son de lo más diversas; sin embargo, sus reivindicaciones se vuelven equivalentes entre sí frente a un excluido. En todo caso, si podemos decir que dos o más elementos se vuelven equivalentes entre sí —esto es que se tornan iguales- es porque son diferentes el uno del otro. En palabras de la propia Mouffe: «[...] la relación de equivalencia no es una en la cual todas las diferencias colapsan en una identidad sino, por el contrario, las diferencias siguen activas» (Mouffe, 2018: 63).

Pues entonces, inevitablemente, surge la pregunta: ¿en dónde radica la diferencia entre un populismo de derecha y otro de izquierda? Nuestro argumento es que la diferencia radica en el tratamiento que le dan a la igualdad, a esa lógica intrínseca que los habita, es decir, la distinción radica en cómo manejan las diferencias, en cómo las organizan en función de la equivalencia. Podemos decir entonces que el populismo de derecha intenta imponer la igualdad a través de un canon uniforme y dominante. Vale decir que, para el populismo de derecha, las nociones de igualdad y diferencias son incompatibles entre sí, por ese motivo es que intenta establecer la igualdad a partir de anular las diferencias. Esto es, establecer un espacio social pleno, completamente ocupado, descifrado, llano, transparente e íntegramente legible, ergo libre de baches, fallas, fisuras o antagonismos en donde transitar sin más la fantasía del pueblo-uno. $\mathrm{Y}$, así, haber logrado que la tensión entre el juego diferencia-equivalencia se haya disuelto en una gran identidad. En definitiva, se trata de construir un espacio social homogéneo en donde las diferencias queden eliminadas en pos de una igualdad planteada en términos de identidad. En cambio, para el popu- 
lismo de izquierda, la igualdad no supone la eliminación de las diferencias, muy por el contrario las soporta, las sostiene en la medida en que se conforma a partir del antagonismo, de la articulación de las heterogeneidades más diversas jugando con la siempre irresoluble tensión entre particularismo y universalismo, entre diferencia y equivalencia. La pregunta que inmediatamente sigue en consecuencia es: ¿no le cabría al populismo de derecha directamente el mote de fascismo o, más precisamente, neofascismo o posfascismo en la medida en que, además de procurar eliminar las diferencias, ha demostrado que puede establecer convenientemente una alianza con el neoliberalismo? Si la respuesta es afirmativa, entonces la distinción entre populismo de izquierda y derecha pierde sentido. Populismo sin más sería así sinónimo de populismo de izquierda y, con ello, se reafirma la tesis política de Laclau de que se trata de una forma que puede habilitar prácticas emancipatorias. Lo demás queda para el neofascismo o posfascismo, esto es, una formación política que no pretende emular punto por punto aquellas experiencias fascistas de los años veinte o treinta del siglo XX, sino que combina una lógica identitaria inmunitaria con neoliberalismo.

\section{DERIVAS FINALES}

A lo largo de este texto hemos intentado, a partir del planteamiento de dos preguntas, aportar renovados elementos que sirvan para el debate sobre el populismo. Sin embargo, lejos de concluir, las respuestas que hemos desarrollado suman derivas que nos invitan a continuar con la reflexión. Mencionaremos aquí brevemente dos para no concluir.

Si aceptamos la respuesta a la pregunta sobre la posibilidad de erradicar el populismo, debemos abandonar aquellos análisis que consideran que el populismo es una mera impostura. Porque si el populismo constituye una dimensión de la política en cuanto tal y, en consecuencia, resulta ser ineliminable, difícilmente pueda dársele el estatuto de un puro engaño. (Claro está, salvo que medie alguna operación discursiva se vuelva equivalente engaño con política.) Es en este sentido que rechazamos, por ejemplo, las lecturas que se basan en las características personales de los líderes que con diversos ardides y astucias llevarían de las narices a los pueblos precipitándolos a horrores significativos.

Esto nos conecta directamente con la segunda deriva. Mouffe critica a quienes, por el simple hecho de que tengan líderes, acusan de autoritarios 
a todos los populismos. Acompañamos a Mouffe en su defensa del lugar del líder, especialmente porque es muy frecuente encontrar una aversión prejuiciosa hacia esta figura que proviene muy generalmente del mundo académico o político progresista o de izquierda. Muchas veces, estos ataques a los liderazgos populistas se basan - como ya mencionamos- en el supuesto del engaño o en la defensa de la primacía de una idea abstracta o autónoma; así, en lugar de la persona del líder, deberíamos tener una idea en su lugar, digamos, el concepto de socialdemocracia, comunismo o socialismo, etc. En decir, una formación política apropiada debería tener una idea — probablemente institucionalizada en un partido político- y al pueblo defendiendo o luchando por esa idea general, mientras que los líderes deberían ocupar un segundo lugar.

Ahora bien, volviendo sobre su distinción entre derechas e izquierda -que trabajamos en relación con la segunda pregunta-, la autora, en cuanto a los liderazgos, sostiene que «[...] todo depende del tipo de relación que se establezca entre el líder y el pueblo. En el caso del populismo de derecha, se trata de una relación muy autoritaria en donde todo viene desde arriba sin participación real de los movimientos de base» (Mouffe, 2018: 70). Podríamos entonces decir que la diferencia entre un liderazgo de izquierda y otro de derecha yace, según Mouffe, simplemente en que el primero atiende a la participación de los movimientos de base y, por ende, la dirección de la relación pueblo-líder va de abajo hacia arriba y la del populismo de derecha fluye en un sentido inverso.

Sin embargo, creemos que la cuestión del líder resulta ser mucho más compleja. En primer lugar, porque tal como lo admite la propia Mouffe, «es muy difícil encontrar ejemplos de movimientos políticos importantes sin líderes» (Mouffe, 2018: 70); es más, podemos agregar que aún las experiencias más horizontales - ya sea aquellas históricas como teóricas - en un cierto punto necesitaron apelar a un líder. Los ejemplos básicos al respecto son, por un lado, el de la democracia ateniense, la cual, en lo que se considera su momento de esplendor, contó con un líder fuerte como Pericles (quizás quepa aquí la especulación sobre si no fue gracias a que hubo un líder como Pericles que alcanzó su edad dorada) y, por otro lado, Rousseau, quien tuvo que introducir la figura del legislador en su Del Contrato Social (1762) para dar consistencia a su tesis sobre la voluntad general.

En segundo lugar, porque podemos pensar en la figura del líder siguiendo la metáfora de Freud de Totem y Tabú (1913) para ilustrar el comienzo de la cultura; el padre autoritario de la horda primitiva tiene que ser muerto y devorado para la constitución de la sociedad y para tener a los liderazgos reconfigu- 
rados como un lugar y, por lo tanto, factible de ser ocupado por cualquiera de los hermanos. Así pues, una vez que el lugar del líder se constituye como tal, quien ocupe ese lugar será siempre uno de los hermanos, un primus inter pares, quien estará siempre en el lugar del padre, pero nunca será el padre. Más aún, siempre estará amenazado por la posibilidad de ser asesinado por los hermanos. Ahora bien, si seguimos a Laclau (2005), no debemos considerar el lugar del líder como un mero espacio vacío. Claro está, siempre que no queramos considerar solo la dimensión formal de la institución del lugar del líder y tengamos también presente la forma de vida política de la comunidad, debemos considerar la mutua contaminación entre quien ocupa el lugar del líder y la naturaleza del propio lugar. Primeramente, porque el líder, como el representante de una articulación populista, necesita presentar la parcialidad que representa como una universalidad (esto es, siguiendo a Laclau, una particularidad que en un cierto momento asume la representación de una totalidad que es inconmensurable respecto de ella misma). Y, en segundo lugar, porque el lugar del lider tiene que tener una encarnadura. Alguien tiene que poner el cuerpo, alguien tiene que encarnar la voluntad popular, la asamblea del pueblo o la idea.

Finalmente, porque hay algo que debe ser considerado sobre el nombre del líder y la dimensión performativa del nombrar. Laclau se refiere a la singularidad que el nombre del líder le imprime en el pueblo: «[...] un conjunto de elementos heterogéneos mantenidos equivalencialmente unidos solo mediante un nombre es, sin embargo, necesariamente una singularidad» (Laclau, 2005: 130). También Laclau nos dice que el nombre del líder se vuelve el fundamento de la equivalencia, ya que «[...] de manera casi imperceptible la lógica de la equivalencia conduce a la singularidad, y esta a la identificación de la unidad del grupo con el nombre del líder» (Laclau, 2005: 130). Por lo tanto, un liderazgo no se trata de una mera voluntad individual que dispone y que puede adquirir o no rasgos autoritarios según el caso, sino que se trata más bien de que el nombre del líder populista (desde nuestra perspectiva, equivalente a populista de izquierda) expresa la singularidad de un pueblo y, por lo tanto, expresa un contexto discursivo único, atravesado por antagonismos, reivindicaciones, legados y herencias comunes. Por ello, el líder nombra una construcción colectiva que largamente lo excede y cuya producción nunca puede llegar a dominar. El nombre propio va mucho más allá de la persona que encarna el liderazgo, de modo tal que no coincide el uno con el otro. En definitiva, el nombre del líder se vuelve una superficie de inscripción de diversas reivindicaciones y antago- 
nismos; en un punto, ya no le pertenece a quien encarna el liderazgo, prueba ello de que el pueblo existe y que responde a la estructura misma de la política. Apuntadas estas derivas, el debate continúa.

\section{BIBLIOGRAFÍA}

Arditi, Benjamín (2003). Populism, or, Politics at the Edges of Democracy. Contemporary Politics, 9(1), 17-31.

Arditi, Benjamín (2005). Populism as Spectre of Democracy. A Response to Canovan. Political Studies, 52, 135-146.

Biglieri, Paula y Guille, Gustavo (2017). The Deconstructivist Laclau. The Undecidable Unconscious: A Journal of Deconstruction and Psychoanalysis, 4, 1-26. doi: 10.1353/ujd.2017.000o

Canovan, Margaret (1999). Trust the people! Populism and the two faces of democracy, Political Studies, vol. XLVII, 1, 2-16.

Coronel, Valeria y Cadahia, Luciana (2018). Populismo republicano: más allá de «Estado versus pueblo», Nueva Sociedad. Recuperado de: http://nuso.org/articulo/populismo-republicano-mas-alla-deestado-versus-pueblo/ [Consultado el 12 de marzo de 2019] .

Fassin, Éric (2018). Left-wing populism. A legacy of defeat: Interview with Éric Fassin. Recuperado de: https://www.radicalphilosophy.com/article/left-wing-populism [Consultado el 14 de noviembre de 2018].

Freud, Sigmund (2013). Totem y Tabú. En Freud, Sigmund. Obras Completas (11-163) Buenos Aires: Amorrortu.

Germani, Gino (1968). Política y sociedad en una época de transición. Buenos Aires: Paidós.

Lacan, Jacques (1985). El seminario. Aún (Libro 20). Buenos Aires: Paidós.

Lacan, Jacques (2003). El seminario. Los cuatro conceptos fundamentales del psicoanálisis (Libro 11). Buenos Aires: Paidós.

Laclau, Ernesto (1990). Nuevas reflexiones sobre la revolución de nuestro tiempo. Buenos Aires: Nueva Visión. 
Laclau, Ernesto (2005). La razón populista. Buenos Aires: FCE.

Laclau, Ernesto (2008). Debates y Combates. Por un nuevo horizonte de la política. Buenos Aires: FCE.

Laclau, Ernesto y Mouffe, Chantal (1985). Hegemonía y estrategia socialista. Hacia una radicalización de la democracia. Buenos Aires: FCE.

Marchart, Oliver (2018). Thinking Antagonism. Political Ontology after Laclau. Edinburgh: Edinburgh University Press.

Mouffe, Chantal (2018). For a Left Populism. London/ New York: Verso.

Murmis, Miguel y Portantiero, Juan Carlos (1971). Estudios sobre los orígenes del peronismo. Buenos Aires: Siglo XXI.

Rinesi, Eduardo (2015). Populismo y republicanismo. Revista Ensambles, 2(3), 84-94.

Rousseau, Jean-Jacques (1988). Del Contrato Social. Madrid: Alianza Editorial.

Worsley, Peter (1969). The Concept of Populism. En Ionescu, Ghita y Gellner, Ernest, (Eds.). Populism: Its Meanings and National Characteristics (82-98). New York: Macmillan.

Žižek, Slavoj (2009). Why Populism Is (Sometimes) Good Enough in Practice, but Not in Theory. En Žižek, Slavoj. In Defense of Lost Causes (264-333). London / New York: Verso. 